\title{
Early life stress and neural development: Implications for understanding the developmental effects of COVID-19
}

\author{
Karen E. Smith ${ }^{1}$ (D) Seth D. Pollak ${ }^{1}$ \\ Accepted: 5 April 2021 / Published online: 23 April 2021 \\ (C) The Psychonomic Society, Inc. 2021
}

\begin{abstract}
Chronic and/or extreme stress in childhood, often referred to as early life stress, is associated with a wide range of long-term effects on development. Given this, the COVID-19 pandemic has led to concern about how stress due to the pandemic will affect children's development and mental health. Although early life stress has been linked to altered functioning of a number of neural and biological systems, there is a wide range of variability in children's outcomes. The mechanisms that influence these individual differences are still not well understood. In the past, studies of stress in childhood focused on the type of events that children encountered in their lives. We conducted a review of the literature to formulate a new perspective on the effects of early life stress on development. This new, topological model, may increase understanding of the potential effects of the COVID-19 pandemic on children's development. This model is oriented on children's perceptions of their environment and their social relationships, rather than specific events. These factors influence central and peripheral nervous system development, changing how children interpret, adapt, and respond to potentially stressful events, with implications for children's mental and physical health outcomes.
\end{abstract}

Keywords Stress $\cdot$ Development $\cdot$ Adversity $\cdot$ Predictability $\cdot$ Safety $\cdot$ COVID-19

The outbreak of a global pandemic associated with COVID19 has brought to the forefront the question of how stress influences children's developmental outcomes. Potential sources of stress related to the pandemic include fear of illness or death of family and friends due to exposure to COVID-19, economic instability due to job loss and the economic recession, school and work closures, and lack of consistency in policies designed to mitigate the effects of the pandemic. All of these potential sources of stress can disrupt typical family dynamics (Gassman-Pines \& Gennetian, 2020). We already see evidence that the COVID-19 pandemic, particularly job and income loss, is associated with more harsh parenting behaviors (Kalil et al., 2020) and increased risk for maltreatment (Lawson et al., 2020), as well as increased risk for behavioral issues in children (Patrick et al., 2020). The potential for stress during the pandemic is intensified by existing inequalities:

Karen E. Smith

kesmith23@wisc.edu

1 Department of Psychology and Waisman Center, University of Wisconsin - Madison, 1500 Highland Avenue, Room 392, Madison, WI 53705, USA low income and minority communities have been disproportionately affected by both the health and economic consequences of the pandemic, having higher death and COVID19 case rates, decreased access to virtual learning environments, and increased food insecurity (Ahmed et al., 2020; Armitage \& Nellums, 2020). Chronic and/or severe stress during early childhood, referred to as early life stress, can have long-lasting consequences for development (Pechtel \& Pizzagalli, 2011; Pollak, 2015). Given this, there has rightfully been concern about how the pandemic will affect children's development (Crawley et al., 2020; Prime et al., 2020). We discuss how research examining the bio-behavioral effects of early life stress can inform our understanding of the potential consequences of the COVID-19 pandemic on children's health.

The term stress refers to the psychological response elicited when an individual perceives themselves to be under threat or challenge. Stress is generally beneficial, producing a range of behavioral and physiological changes designed to address the perceived threat. However, extended activation of stress response systems can have negative physical and mental health outcomes (McEwen, 2017b; Sapolsky, 2015). A key aspect of stress is that stress responses are elicited by an individual's 
perception of something as stressful rather than the events to which they are exposed. This means variability in individuals' perceptions of stress is an integral contributor to individual differences in psychological and physiological stress responses (Brosschot, 2017; Peters et al., 2017).

Historically, research on stress and child development has tended to focus on the types of external events children encounter, such as war exposure, abuse, neglect, or food insecurity. More recently, researchers have started to incorporate a role for children's perceptions of their environments as a way to better understand the effects of stress (Allwood et al., 2017; Danese \& Widom, 2020). While somewhat mixed (Negriff, 2020), this research, along with that in adults and nonhuman animals suggesting that perceptions are critical in shaping experiences of stress, indicates a need for conceptualizations of early life stress that do not rely solely on events. A new approach, termed "topological," reframes consideration of how early life stress might affect biological stress response mechanisms by emphasizing how children understand and interpret what is happening to them (Figure 1; Smith \& Pollak, 2020). In this approach, it is not the type or category of an event to which a child is exposed that is meaningful, but rather how various factors influence how an event or environment is perceived and interpreted by the child. This means that when examining the potential effects of the COVID-19 pandemic on development, it is important to examine factors that may be shift how children perceive and interpret the pandemic alongside specific potential stressors, such as economic strain and parental job loss.

The COVID-19 pandemic is characterized by a number of aspects that have the potential to result in chronic, extreme perceptions of stress for many individuals. Changing and inconsistent messaging from public health officials and policy makers along with abrupt changes in policies tied to the COVID-19 pandemic - moving in and out of stay at home orders and lockdowns, schools closing, reopening, and closing again, and piecemeal mask policies that lack enforcement-all have the potential to increase feelings of uncertainty and unpredictability associated with the pandemic. Additionally, social distancing policies and workplace and school closures can increase feelings of social isolation, which could exacerbate perceptions of stress linked to the pandemic. Evidence suggests that both children and adults are experiencing increases in stress, perceived social isolation, depression, and anxiety related to the pandemic (Lee et al., 2020; Li \& Wang, 2020; Tull et al., 2020). However, there has been a range of variability in how stressful and isolating individuals find the pandemic (Ellis et al., 2020; Sutin et al., 2020). Taking an approach towards stress that incorporates a role for children's perceptions of the pandemic in influencing their experiences of stress can aid with understanding why children may be differently affected by the COVID-19 pandemic. In this manuscript, we apply a topological approach to examine potential effects of the COVID-19 pandemic on children's development, reviewing the role of perceptions of predictability and safety, particularly perceptions of safety related to having strong, supportive social relationships, in shaping children's responses to stress.

\section{Early life stress and development: A brief overview}

To date, early life stress, as measured by children's event exposures, has been linked to consistent patterns of effects

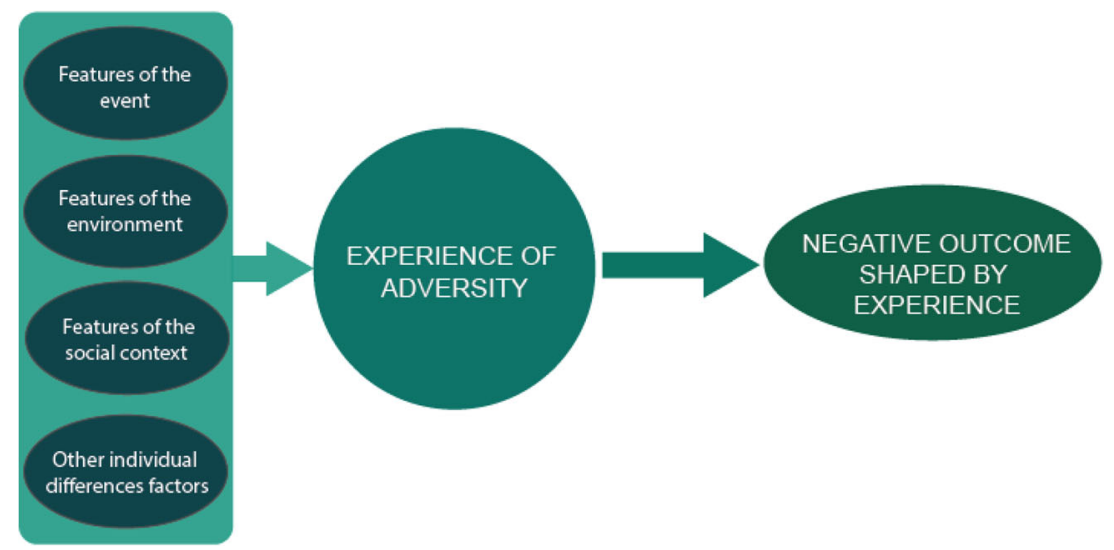

Fig. 1. Topological approach for conceptualizing early adversity (figure adapted from Smith \& Pollak, 2020). Factors or dimensions surrounding the potentially adverse events children are exposed to contribute to the child's experience, which then activates relevant bio-behavioral responses to those circumstances. Meaningful factors might include features of the event (e.g., intensity, chronicity, developmental timing); features of the environment (e.g., predictability, contingency, controllability); and features of the child's social context (e.g., presence of safety, social support), as well as other individual differences factors, such as genetics, temperament, or previous life history. In the context of the COVID-19 pandemic, this suggests that children's outcomes will not be determined solely by their existing environment. Instead, they will likely be more influenced by factors related to features, such as predictability, controllability, and safety, that shape how children make meaning of the pandemic 
on neural development. Indeed, early life stress is associated with altered functioning of the hypothalamic pituitary adrenal (HPA) axis, autonomic nervous system, and immune system (Alkon et al., 2014; Danese \& Lewis, 2017; Koss \& Gunnar, 2017; Loman \& Gunnar, 2010). These systems are critical to facilitating motived psychological and behavioral responses to the environment, particularly environmental threats and challenges (Berntson \& Cacioppo, 2004; B. S. McEwen, 2019b). The effects of early life stress on peripheral stress response systems are thought to be a result of altered neural plasticity in circuits integral to stress responses, including the prefrontal cortex (PFC), hippocampus, amygdala, and striatal circuits (Fareri \& Tottenham, 2016; C. A. McEwen \& McEwen, 2017). Many of these changes have been hypothesized to represent adaptive responses to environments of high threat, which become problematic within the broader social context (Boyce \& Ellis, 2005; Obradović et al., 2016). However, there also is a wide range of variation in children's outcomes after exposure to early life stress (Hostinar \& Gunnar, 2013b; Palacios-Barrios \& Hanson, 2019). We understand relatively little about what drives this variability (Smith \& Pollak, 2020). This suggests a need for alternative approaches aimed at examining the bio-behavioral effects of childhood stress that are not solely focused on children's event exposure.

\section{Perceptions not events determine variability in stress responses}

While the early childhood literature has tended to focus on whether children have been exposed to events deemed by researchers to be stressful or adverse, the vast majority of evidence with adults and nonhuman animals suggests that neural, physiological, and behavioral stress responses are not primarily influenced by the type of event to which an organism is exposed (Berntson \& Cacioppo, 2004; McEwen \& McEwen, 2012; Sapolsky, 2015). There is a range of variability in how both humans and nonhuman animals respond to the same type of stressor. Nonhuman animals demonstrate distinct behavioral responses to the same event, and this variability in behavior is tied to differential activation in the sympathetic adrenal-medullar, hypothalamic gonadal, and HPA systems (Buwalda et al., 1992; Korte et al., Korte et al., 1992, Korte et al., 1995; Veenema et al., 2003). Humans demonstrate similar variability in stress responses. This variability is observed in indices including cardiac autonomic responsivity (Berntson et al., 1994; Berntson \& Cacioppo, 2004), immune reactivity (Cohen \& Hamrick, 2003; Manuck et al., 1991), cortisol responses (Buchanan et al., 2006; Roy et al., 2001; Vedhara et al., 2000), and neural responses in the hippocampus and prefrontal cortex (Pruessner et al., 2008; Wager et al., 2009). These findings support the idea that the type of event or environment to which an individual is exposed is not directly tied to a specific neurobiological response or outcome.

Given variation in stress responses does not appear to be attached to a particular environment or event, this raises the question of what does drive variability in stress responses. Evidence suggests that individuals' neurobiological stress responses and outcomes are more influenced by their perception of an event or environment as adverse (Brosschot et al., 2017; Goldstein \& McEwen, 2002; Lazarus, 1990; McEwen, 2019a; Peters et al., 2017; Sapolsky, 2015). To illustrate, perceptions of controllability and predictability are two of the primary factors that influence whether a potential stressor is perceived as stressful (Bollini et al., 2004; Henry, 1992; Mormede et al., 1988; Muller, 2012). In humans, individual differences in perceptions of control have been linked to differential cortisol responses to acute laboratory stress, differences in brain volume, and differences in brain reactivity to stress in regions, including the hippocampus, amygdala, and prefrontal cortex (Harnett et al., 2015; Hashimoto et al., 2015; Pruessner et al., 2005). Other factors that influence how individuals interpret potential stressors include whether individuals perceive themselves to be in a safe or dangerous environment and their perceptions of their coping resources (Blascovich, 2008; Jamieson et al., 2018; Mendes et al., 2001).

This means that perceptions of stress, and associated neurobiological responses, can occur in the absence of any specific identifiable environmental event. Examples of this include rumination over previous experience or events, anxiety about future events, and feelings of loneliness and social isolation despite having social relationships available (Cacioppo et al., 2011; Hilt \& Pollak, 2013; Ottaviani et al., 2016; Paulesu et al., 2010). Together this research indicates that any approach aimed at understanding individual differences in outcomes after stress exposure needs to incorporate the factors that shape individuals' perceptions and interpretations of their events. Additionally, it suggests that variability in individuals' responses to the COVID-19 pandemic will be linked to their perception of the pandemic.

\section{Perception, childhood adversity, and the COVID-19 pandemic}

Given the important role of perception in influencing variability in stress responses, it is unlikely that all children will respond to the COVID-19 pandemic in a similar manner. There are a wide range of factors that likely shape and modulate children's perceptions and interpretation of environmental adversity, including perceived control and predictability, perceived safety, genetics, timing, intensity, and chronicity of adversity, and gene by environment interactions, among many others (Hostinar \& Gunnar, 2013a; McEwen \& McEwen, 2017; Smith \& Pollak, 2020). Given the high risk of 
unpredictability and social isolation associated with the COVID-19 pandemic, we focused on recent research, which suggest integral roles for perceptions of predictability and safety, particularly perceived safety related to presence of sensitive and supportive social relationships, in shaping children's interpretations of their early environment.

Perceptions of predictability Predictability is defined as the degree to which accurate predictions can be made about future events based on current ones. Contingency, often characteristic of predictability, refers to the likelihood of one event or action being followed by another (Frankenhuis, 2016; Hasson, 2017). As stated previously, perceptions of control and predictability are two of the most critical factors shaping perceptions of stress (Peters et al., 2017; Sapolsky, 2004). This is especially relevant to the COVID-19 pandemic, because it has been accompanied by many factors that increase individuals' risk for high levels of perceived unpredictability and uncontrollability. Limited knowledge, especially early in the pandemic, about the virus and its transmission, along with conflicting and rapidly changing information and recommendations from elected and public health officials, all have the potential to contribute to high perceived unpredictability and uncontrollability. In the literature linking stress in early childhood to development predictability has been of increasing interest. Given this, we focused our discussion on how perceptions of predictability shape development and the implications this has for how children may respond to the COVID-19 pandemic. However, we recognize predictability and controllability are highly interrelated (Peters et al., 2017; Sapolsky, 2015) and likely both play important roles in influencing children's interpretations of their early environment and the COVID-19 pandemic.

A lack of predictability in the environment leads to perceptions of uncertainty, volatility, and uncontrollability, which can result in extended activation of stress response systems (Soltani \& Izquierdo, 2019). This extended activation alters brain growth and architecture in regions, such as the PFC, amygdala, and hippocampus, which undermines stress regulation and coping (Peters et al., 2017). Parent-child relationships are stereotypically repetitive, highly predictable, and marked by contingent parental responses - adult caregivers reliably respond to infant cries, comfort a child who is hurt, and provide support to a child who is dysregulated (Fisher et al., 2016; Hallers-Haalboom et al., 2017). Lack of predictable and contingent input from caregivers affects children's expectations of the environment, leading to uncertainty and perceptions of a lack of control and vulnerability (Chen \& Baram, 2016; Harms et al., 2018).

Indeed, evidence from nonhuman animals suggests that predictable and contingent parental responding plays an important role in shaping learning processes, particularly social learning (Baram et al., 2012; Risbrough et al., 2018; Zajac et al., 2019). In rodents, variations in maternal care, measured via licking and grooming behaviors, have been associated with poorer learning and memory (Barha et al., 2007; Liu et al., 2000) and altered stress regulation (Champagne et al., 2008; Weaver et al., 2004). These effects appear to be dependent on changes in hippocampal (Champagne et al., 2008; Liu et al., 2000), prefrontal (Monroy et al., 2010; Zhang et al., 2005), and amygdala (Caldji et al., 1998; Fries et al., 2004) synaptic plasticity, areas that together play an important role in both stress responsivity and learning and memory (Eichenbaum, 2017; McEwen, 2017a). Variations in maternal care are linked to epigenetic changes in glucocorticoid receptors (Turecki \& Meaney, 2016; Weaver et al., 2004) and alterations in both glucocorticoid and mineralocorticoid receptor expression (Champagne et al., 2008; van Hasselt et al., 2012). This is suggestive of changes in HPA functioning. Additionally, these changes appear to be driven by the type of maternal behavior to which pups are exposed. Crossfostering infants of low-licking and grooming mothers with high-licking and grooming mothers appears to reverse some of these changes at the neural and behavioral levels (Liu et al., 2000; Weaver et al., 2004). Recent evidence suggests that these effects are not solely due to changes in amount of high-licking and grooming behaviors mothers exhibit towards their pups, but rather the predictability of these behaviors (Risbrough et al., 2018). More fragmented maternal behaviors are associated with greater alterations in stress response systems (Davis et al., 2017; Glynn \& Baram, 2019).

While little research has attempted to directly assess predictability of the early environment in humans, growing evidence indicates that predictability of parental inputs contributes to children's outcomes above and beyond the types of inputs. Predictability of parental inputs (measured by calculating entropy rate for maternal auditory, visual, and tactile inputs during the parent-child interaction) demonstrates a stronger association with children's cognitive outcomes than the type of inputs (measured through coded maternal sensitivity, positive regard, and intrusiveness during a parent-child interaction) (Davis et al., 2017). Longitudinal research assessing early influences on adolescents' externalizing behaviors finds that unpredictability of the environment during childhood, quantified using changes in maternal employment, changes in residence, and changes in cohabitation, is associated with increased externalizing behaviors in adolescence. However, type of adversity (in this study, SES) is not (Doom et al., 2016).

Research in rodents suggests that these effects are a result of altered functioning in prefrontal-hippocampal-amygdala circuits. Unpredictable maternal inputs are associated with altered connectivity between the medial PFC and amygdala (Bolton et al., 2018) and decreased dendritic arborization in the hippocampus (Molet et al., 2016). These effects on prefrontal-amygdala-hippocampal circuits are apparent 
beyond effects produced by types of maternal inputs. Additionally, the effects of predictability on neural circuits are linked to PTSD and depressive-like behaviors as well as deficits in learning (Risbrough et al., 2018). Together, this body of work suggests that variation in the predictability, stability, and/or degree of contingent responding of adult caregivers is a factor in shaping children's responses to adversity through alterations in prefrontal cortical and subcortical stress response circuits. It indicates that assessment of predictability of early environments has the potential to provide increased insight into individual differences in the neurobiological effects of early adversity on child development-variability that is not captured when focusing solely on types of adverse events. This also means that children's experiences of stress associated with the COVID-19 pandemic will be at least partially shaped by the extent to which the pandemic shifts their perceptions of predictability.

Perceptions of safety Throughout the COVID-19 pandemic, public health officials have recommended individuals and policy makers enforce social distancing measures aimed at limiting transmission of the virus. Depending on where an individual lives, these policies have included closing of nonessential businesses, school closures and limitations of in-person education, limiting the number of people outside a single household who can gather, and encouraging all individuals to stay at home and limit interaction with nonhousehold members as much as possible. In addition to being inconsistent and unpredictable (i.e., schools closing, reopening, and then closing again), these measures have the potential to increase the risk of children feeling socially isolated and lacking social support. In adults, having high-quality and supportive social relationships is associated with reduced perceptions of stress as well as dampened psychological and physiological responses to laboratory stress (for review see Eisenberger, 2013; Hawkley \& Capitanio, 2015). These effects are thought to in part result from high-quality and supportive social relationships acting as a signal of safety (Beckes \& Coan, 2011; Brosschot et al., 2017). Together this suggests social distancing measures implemented in response to the COVID-19 pandemic may alter children's experiences of stress associated with the pandemic by shifting perceptions of safety.

Increasingly, research supports a role for perceived safety in contributing to variations in children's responses to stress. Safety/security in early childhood has been characterized in a variety of different ways. Parental presence/adult "buffering," sensitivity, responsivity, and support are all thought to be cues of safety (Brody et al., 2019; Gunnar et al., 2015). Lack of parental input, through isolation, maternal separation, neglect, or abusive parenting behaviors are all thought to represent cues of lack of safety (Callaghan \& Tottenham, 2016; Sanchez et al., 2015). Cues of safety early in development play an important role in engaging the prefrontal circuits that inhibit threat response circuits (Porges, 2015). This in turn will have implications for how children perceive and interact with their environment later in life (Grupe \& Nitschke, 2013; Mobbs et al., 2007).

Indeed, evidence from nonhuman primate and rodent models supports this, finding that early parental presence plays an important role in inhibiting neurobiological threat response systems. Both rodent pups and infant primates demonstrate reduced glucocorticoid release and decreased amygdala activation in the presence of the mother (Sanchez et al., 2015; Sullivan \& Opendak, 2018). However, in cases of abusive maternal rearing, maternal presence does not appear to exhibit buffering effects. Under these circumstances, rodent pups and primate infants demonstrate enhanced glucocorticoid responses to stress (Moriceau et al., 2009; Sanchez et al., 2015) along with alterations in both the structure and function of the amygdala and prefrontal cortex (Nephew et al., 2017; Rincón-Cortés \& Sullivan, 2016; Spinelli et al., 2009). From this literature, it is clear parental presence, a salient early cue of safety, is important to supporting typical development of the neurobiological stress response systems.

There is evidence indicative of similar early regulatory effects of parental presence on the development of stress response systems in humans (Gunnar et al., 2015; Tottenham, 2015). Parallel to the rodent and primate literatures, parental presence has been demonstrated to dampen both cortisol (Hostinar et al., 2015; Seltzer et al., 2010) and amygdala reactivity (Gee et al., 2014) to stress in children. There also is evidence that disruptions of these early relationships, through maltreatment, is associated with altered prefrontal-amygdala connectivity (Fan et al., 2014). These changes in connectivity have been linked to children's risk for psychopathology (Gee et al., 2013; Herringa et al., 2016). It is difficult to establish causality from this type of correlational research (i.e., these effects could be a result of shared genetic factors between parent and child). However, this literature in combination with the animal research described above points to alterations of typical development of prefrontal-amygdala circuits in children lacking early cues of safety that have implications for their behaviors and mental health.

Additionally, in cases of maltreatment or adversity where children still receive high levels of support from their parents, the effects of adversity on prefrontal-amygdala circuits are mitigated. Adolescents living in poverty show altered connectivity in prefrontal cortical networks involved in executive functioning and emotion regulation, but not if they reported having high levels of parent support (Brody et al., 2019). Additionally, support provided by other adults or peers may diminish some of the bio-behavioral effects of adversity. Reported social support from family and friends is associated with reduced risk of psychopathology in children who experience maltreatment (McLafferty et al., 2018; van Harmelen et al., 2016). Children who report having more higher quality 
peer relationships and adolescents who spend more time with their friends outside of school demonstrate reduced neural activation in circuits involved in pain processing to social rejection (Masten et al., 2012; Will et al., 2016). Adolescents who report lower levels of perceived social isolation also report decreased levels of perceived stress and reduced risk for depression, anxiety, and poor physical health (Harris et al., 2013; Ladd \& Ettekal, 2013; Vanhalst et al., 2013). This suggests that, at least in humans, individuals outside of the parent-child relationship may be able to supplement these safety cues when they break down.

Consistently incorporating assessment of factors that represent early cues of safety, such as parental and peer support, when studying how children respond to early adversity, has the potential to greatly illuminate the neurobiological mechanisms through which negative environments shape development. Additionally, taking this type of approach can inform our understanding of individual variability in responses to the COVID-19 pandemic. Children may not necessarily experience increased isolation merely, because they are spending more time at home and less time at school. Rather, their perceptions of isolation and lack of support are going to vary based on the support they have at home from parents and other family members, their own relationships with parents and family members at home, and their access to relationships with other peers and adults. These perceptions likely will provide more insight into any long-term developmental effects of the pandemic.

\section{Developmental effects of the COVID-19 pandemic: Informing policy}

There has rightfully been a large amount of attention focused on how the stress associated with the pandemic will affect children's development long term and how to develop policies aimed at aiding those children at greatest risk for chronic or extreme stress associated with the pandemic (Dalton et al., 2020; Prime et al., 2020; Richtel, 2020). Indeed, the risk of experiencing the pandemic as a chronic and extreme stressor is especially high for children already in environments characterized by inequality and disparity (Gassman-Pines \& Gennetian, 2020; Kalil et al., 2020). These are children for whom school and other extracurricular activities may represent some of the few predictable, reliable, and controllable aspects in their life where they have access to supportive relationships with peers and adults. Removing these structures not only increases these children's risk of experiencing the pandemic as a chronic, extreme stressor but has the potential to exacerbate the stress they are exposed in the home and deplete any available coping resources they may have. This in turn increases the risk for chronic, extended activation of psychological, neural, and behavioral stress response systems and long-term negative physical and mental health outcomes.

Despite the COVID-19 pandemic increasing risk for chronic and extreme stress, the research we have reviewed above suggests that the pandemic and concomitant policies, such as school closures, are not necessarily going to equate to negative developmental outcomes for all children later in life. Instead, it indicates that the effects of such a population level event will be shaped by how children are perceiving and interpreting this event rather than the event itself. Indeed, recent research using a machine learning approach to examine what kinds of events typically characterized as stressors are associated with a range of academic and health outcomes found that no one event was particularly predictive of children's outcomes (Salganik et al., 2020). Additionally, reported exposure to child abuse or neglect has recently been demonstrated to more predictive of children's mental health outcomes than exposure identified through court reports (Danese \& Widom, 2020). Given parental inputs of predictability and support seem particularly critical for shaping perceptions of stress, it is likely that, for children who are in a home environment in which parents are continuing to provide support, love, and affection and attempting to maintain consistency and predictability, the long-term effects of the pandemic on development may be buffered.

Taking a perception focused topological approach to understanding the effects of COVID-19 on development means that we should be careful about assuming which children are more or at less risk. As illustrated above, there are a plethora of factors not tied to specific events or environmental circumstances that will influence children's meaning making related to the pandemic. This also means there is ample opportunity for adults to buffer and intervene against the negative effects of pandemic related stress. At the same time, there are widening disparities related to economic and racial inequality, especially in the United States. These disparities do place a large proportion of families at significantly greater risk of chronic, extreme stress associated with the pandemic (Boyraz \& Legros, 2020; Fortuna et al., 2020). These also are the families that likely will have decreased access to any policies or interventions developed to aid families and parents in establishing supportive, predictable, and controllable environments (Araya et al., 2018; Lê Cook et al., 2017). Economic and racial inequality has already been linked to a range of differential outcomes for families during the pandemic. Low-income and minority communities have significantly higher cases and deaths from COVID-19, decreased participation of children in virtual learning environments, and many of these parents are having to choose between a job and income or childcare for young children (Ahmed et al., 2020; Armitage \& Nellums, 2020; Chen et al., 2020). It is critical that opportunities for intervention take into consideration the significant disparities associated with inequality in the United States. 
In implementing policies designed to provide economic and social support, through income supplements, rent moratoriums or assistance, and food aid programs, such as the Supplemental Nutrition Assistance Program (SNAP), it can be helpful for both researchers and policy makers to examine how these policies may shift how parents and children are perceiving and coping with their environments. Policies that both provide much needed economic relief along with alleviating feelings of uncontrollability, unpredictability, and lack of safety will likely have the most efficacy. Of particular interest are strategies that work to provide families with the resources to establish reliability and predictability at home to aid in management of stress. Exploring how parents' own stress about economic resources, meals, and potential job loss can be alleviated and finding new options, such as outdoor classrooms or activities in which social distancing can be maintained to continue to allow for peer interaction and engagement, likely can aid in supporting families and children during the pandemic. These all represent areas in which intervention could potentially help to shift children's perceptions of the pandemic towards those of safety rather than threat. Indeed, interventions that demonstrate the most efficacy for improving outcomes for children in high-stress environments are those that focus on the level of the family or both the family and school (Bakermans-Kranenburg et al., 2003; Finlon et al., 2015). Additionally, interventions designed to directly shift how individuals perceive and attend to information in their environments, such as cognitive behavioral therapy (Butler et al., 2006; Hofmann et al., 2012), may have utility. In sum, the long-term developmental outcomes of children related to the COVID-19 pandemic are likely not going to be uniform and will be linked to other factors that shift children's perceptions of stress and threat associated with the pandemic. Better understanding what and how those function can help support and aid children in coping with any stress related to the COVID-19 pandemic.

\section{Conclusions}

Under typical circumstances, early life stress has long-lasting and substantive consequences for development, making it a considerable public health and humanitarian problem. The COVID-19 pandemic has only exacerbated these issues, placing children and families already at risk of long-term psychological, behavioral, and health outcomes due to chronic or extreme stress at even greater risk - a risk that increases the longer the pandemic continues. An evidence-based approach towards identifying those children and families that may be most at risk of chronic and extreme experiences of stress related to the pandemic is critical to implementing policies designed to provide these families with effective tools and interventions to aid them in coping with stress. Key to this mission is elucidating the neural, physiological, and behavioral mechanisms involved in individual differences in children's outcomes.

Because growing evidence suggests that individual differences in stress responses are not accounted for by the events to which children are exposed, it is imperative that we adopt alternative approaches towards understanding early life stress. Incorporating assessment of factors, including predictability, controllability, and perceived safety, that shift perceptions of stress has promise towards illuminating the underlying mechanisms supporting variability in children's responses to stress (Smith \& Pollak, 2020). Taking this type of approach towards understanding childhood stress has the potential to greatly inform our understanding of why children respond to the COVID-19 pandemic differently and which children may be in most need of policy aid and intervention. It also can aid in policy-level interventions, as it may be possible to identify large groups of individuals who may be more likely to lack predictability or social support-i.e., low SES children whose parents are having to choose between employment and childcare. Additionally, it can more broadly illuminate our understanding of the bio-behavioral mechanism through which early environments influence development and why children end up in different places after experiencing similar events. A topological approach that is oriented around children's perceptions, rather than just the external stimuli they encounter in the world, can provide avenues through which to think differently about how to support and aid families and children struggling to cope with the pandemic. Longer-term, it can provide researchers and policy makers with better tools to address the important societal issues linked to experiences of stress early in life.

Funding This work was supported by the National Institute of Mental Health [R01MH61285 (SDP), T32MH018931-30 (KES)] and by a core grant to the Waisman Center from the National Institute of Child Health and Human Development [U54 HD090256]. Karen Smith ORCID: 0000-0002-6689-7346; Seth Pollak ORCID: 0000-0001-51849846.

\section{References}

Ahmed, F., Ahmed, N., Pissarides, C., \& Stiglitz, J. (2020). Why inequality could spread COVID-19. The Lancet Public Health, 5(5), e240. https://doi.org/10.1016/S2468-2667(20)30085-2

Alkon, A., Boyce, W. T., Tran, L., Harley, K. G., Neuhaus, J., \& Eskenazi, B. (2014). Prenatal adversities and latino children's autonomic nervous system reactivity trajectories from 6 months to 5 years of age. PLoS ONE, 9(1), 1-8. https://doi.org/10.1371/ journal.pone. 0086283

Allwood, M. A., Gaffey, A. E., Vergara-Lopez, C., \& Stroud, L. R. (2017). Stress through the mind of the beholder: Preliminary differences in child and maternal perceptions of child stress in relation to 
child cortisol and cardiovascular activity. Stress, 20(4), 341-349. https://doi.org/10.1080/10253890.2017.1336617

Araya, R., Zitko, P., Markkula, N., Rai, D., \& Jones, K. (2018). Determinants of access to health care for depression in 49 countries: A multilevel analysis. Journal of Affective Disorders, 234(January), 80-88. https://doi.org/10.1016/j.jad.2018.02.092

Armitage, R., \& Nellums, L. B. (2020). Considering inequalities in the school closure response to COVID-19. The Lancet Global Health, 8(5), e644. https://doi.org/10.1016/S2214-109X(20)30116-9

Bakermans-Kranenburg, M. J., van IJzendoorn, M. H., \& Juffer, F. (2003). Less is more: Meta-analyses of sensitivity and attachment interventions in early childhood. Psychological Bulletin, 129(2), 195-215. https://doi.org/10.1037/0033-2909.129.2.195

Baram, T. Z., Davis, E. P., Obenaus, A., Sandman, C. A., Small, S. L., Solodkin, A., \& Stern, H. (2012). Fragmentation and Unpredictability of Early-Life Experience in Mental Disorders. American Journal of Psychiatry, 169(9), 907-915. https://doi.org/ 10.1176/appi.ajp.2012.11091347

Barha, C. K., Pawluski, J. L., \& Galea, L. A. (2007). Maternal care affects male and female offspring working memory and stress reactivity. Physiology \& Behavior, 92(5), 939-950. https://doi.org/10.1016/J. PHYSBEH.2007.06.022

Beckes, L., \& Coan, J. A. (2011). Social baseline theory: The role of social proximity in emotion and economy of action. Social and Personality Psychology Compass, 5(12), 976-988. https://doi.org/ 10.1111/j.1751-9004.2011.00400.x

Berntson, G. G., \& Cacioppo, J. T. (2004). Heart rate variability: Stress and psychiatric conditions. In Dynamic Electrocardiography (pp. 57-64).

Berntson, G. G., Cacioppo, J. T., Binkley, P. F., Uchino, B. N., Quigley, K. S., \& Fieldstone, A. (1994). Autonomic cardiac control. III. Psychological stress and cardiac response in autonomic space as revealed by pharmacological blockades. Psychophysiology, 31, 599-608. https://doi.org/10.1111/j.1469-8986.1994.tb02352.x

Blascovich, J. (2008). Challenge and threat. In A. J. Elliot (Ed.), Handbook of approach and avoidance motivation (pp. 431-446). Psychology Press.

Bollini, A. M., Walker, E. F., Hamann, S., \& Kestler, L. (2004). The influence of perceived control and locus of control on the cortisol and subjective responses to stress. Biological Psychology, 67, 245260.

Bolton, J. L., Molet, J., Regev, L., Chen, Y., Rismanchi, N., Haddad, E., Yang, D. Z., Obenaus, A., \& Baram, T. Z. (2018). Anhedonia following early-life adversity involves aberrant interaction of reward and anxiety circuits and is reversed by partial silencing of amygdala corticotropin-releasing hormone gene. Biological Psychiatry, 83(2), 137-147. https://doi.org/10.1016/J.BIOPSYCH.2017.08.023

Boyce, W. T., \& Ellis, B. J. (2005). Biological sensitivity to context: I. An evolutionary-developmental theory of the origins and functions of stress reactivity. Development and Psychopathology, 17(2), 271301. http://www.ncbi.nlm.nih.gov/pubmed/16761546

Boyraz, G., \& Legros, D. N. (2020). Coronavirus Disease (COVID-19) and Traumatic Stress: Probable Risk Factors and Correlates of Posttraumatic Stress Disorder. Journal of Loss and Trauma, O(0), 1-20. https://doi.org/10.1080/15325024.2020.1763556

Brody, G. H., Yu, T., Nusslock, R., Barton, A. W., Miller, G. E., Chen, E., Holmes, C., McCormick, M., \& Sweet, L. H. (2019). The protective effects of supportive parenting on the relationship between adolescent poverty and resting-state functional brain connectivity during adulthood. Psychological Science, 095679761984798. https://doi.org/10.1177/0956797619847989

Brosschot, J. F. (2017). Ever at the ready for events that never happen. European Journal of Psychotraumatology, 8(1). https://doi.org/10. 1080/20008198.2017.1309934

Brosschot, J. F., Verkuil, B., \& Thayer, J. F. (2017). Exposed to events that never happen: Generalized unsafety, the default stress response, and prolonged autonomic activity. Neuroscience \& Biobehavioral Reviews, 74, 287-296. https://doi.org/10.1016/j.neubiorev.2016.07. 019

Buchanan, T. W., Tranel, D., \& Adolphs, R. (2006). Impaired memory retrieval correlates with individual differences in cortisol response but not autonomic response. Learning \& Memory (Cold Spring Harbor, N.Y.), 13(3), 382-387. https://doi.org/10.1101/lm.206306

Butler, A. C., Chapman, J. E., Forman, E. M., \& Beck, A. T. (2006). The empirical status of cognitive-behavioral therapy: A review of metaanalyses. Clinical Psychology Review, 26(1), 17-31. https://doi.org/ 10.1016/j.cpr.2005.07.003

Buwalda, B., Koolhaas, J. M., \& Bohus, B. (1992). Behavioral and cardiac responses to mild stress in young and aged rats: Effects of amphetamine and vasopressin. Physiology \& Behavior, 51(2), 211-216. https://doi.org/10.1016/0031-9384(92)90133-M

Cacioppo, J. T., Hawkley, L. C., Norman, G. J., \& Berntson, G. G. (2011). Social isolation. Annals of the New York Academy of Sciences, 1231(1), 17-22. https://doi.org/10.1111/j.1749-6632. 2011.06028.x

Caldji, C., Tannenbaum, B., Sharma, S., Francis, D., Plotsky, P. M., \& Meaney, M. J. (1998). Maternal care during infancy regulates the development of neural systems mediating the expression of fearfulness in the rat. Proceedings of the National Academy of Sciences, 95(9), 5335-5340. https://doi.org/10.1073/PNAS.95.9.5335

Callaghan, B. L., \& Tottenham, N. (2016). The neuro-environmental loop of plasticity: A cross-species analysis of parental effects on emotion circuitry development following typical and adverse caregiving. Neuropsychopharmacology, 41(1), 163-176. https://doi.org/10. 1038/npp.2015.204

Champagne, D. L., Bagot, R. C., Hasselt, F. van, Ramakers, G., Meaney, M. J., Kloet, E. R. de, Joëls, M., \& Krugers, H. (2008). Maternal care and hippocampal plasticity: Evidence for experience-dependent structural plasticity, altered synaptic functioning, and differential responsiveness to glucocorticoids and stress. Journal of Neuroscience, 28(23), 6037-6045. https://doi.org/10.1523/ JNEUROSCI.0526-08.2008

Chen, J. T., Waterman, P. D., \& Krieger, N. (2020). COVID-19 and the unequal surge in mortality rates in Massachusetts, by city/town and ZIP Code measures of poverty, household crowding, race/ethnicity, and racialized economic segregation. HCPDS Working Paper, 19(2). https://www.bostonglobe.com/2020/05/09/nation/disparitiespush-coronavirus-death-rates-higher/

Chen, Y., \& Baram, T. Z. (2016). Toward understanding how early-life stress reprograms cognitive and emotional brain networks. Neuropsychopharmacology, 41(1), 197-206. https://doi.org/10. 1038/npp.2015.181

Cohen, S., \& Hamrick, N. (2003). Stable individual differences in physiological response to stressors: Implications for stress-elicited changes in immune related health. Brain, Behavior, and Immunity, 17(6), 407-414. https://doi.org/10.1016/S0889-1591(03)00110-7

Crawley, E., Loades, M., Feder, G., Logan, S., Redwood, S., \& Macleod, J. (2020). Wider collateral damage to children in the UK because of the social distancing measures designed to reduce the impact of COVID-19 in adults. BMJ Paediatrics Open, 4(1), e000701. https://doi.org/10.1136/bmjpo-2020-000701

Dalton, L., Rapa, E., \& Stein, A. (2020). Protecting the psychological health of children through effective communication about COVID19. The Lancet Child and Adolescent Health, 4(5), 346-347. https:// doi.org/10.1016/S2352-4642(20)30097-3

Danese, A., \& Lewis, S.J. (2017). Psychoneuroimmunology of early-life stress: The hidden wounds of childhood trauma? Neuropsychopharmacology, 42(1), 99-114. https://doi.org/10. 1038/npp.2016.198

Danese, A., \& Widom, C. S. (2020). Objective and subjective experiences of child maltreatment and their relationships with 
psychopathology. Nature Human Behaviour. https://doi.org/10. 1038/s41562-020-0880-3

Davis, E. P., Stout, S. A., Molet, J., Vegetabile, B., Glynn, L. M., Sandman, C. A., Heins, K., Stern, H., \& Baram, T. Z. (2017). Exposure to unpredictable maternal sensory signals influences cognitive development across species. Proceedings of the National Academy of Sciences, 201703444. https://doi.org/10.1073/pnas. 1703444114

Doom, J. R., Vanzomeren-Dohm, A. A., \& Simpson, J. A. (2016). Early unpredictability predicts increased adolescent externalizing behaviors and substance use: A life history perspective. Development and Psychopathology, 28(4pt2), 1505-1516. https://doi.org/10.1017/ S0954579415001169

Eichenbaum, H. (2017). Prefrontal-hippocampal interactions in episodic memory. Nature Reviews Neuroscience, 18(9), 547-558. https://doi. org/10.1038/nrn.2017.74

Eisenberger, N. I. (2013). An empirical review of the neural underpinnings of receiving and giving social support: Implications for health. Psychosomatic Medicine, 75(6), 545-556. https://doi.org/10.1097/ PSY.0b013e31829de2e7

Ellis, W. E., Dumas, T. M., \& Forbes, L. M. (2020). Physically isolated but socially connected: Psychological adjustment and stress among adolescents during the initial COVID-19 crisis. Canadian Journal of Behavioural Science, 52(3), 177-187. https://doi.org/10.1037/ cbs0000215

Fan, Y., Herrera-Melendez, A. L., Pestke, K., Feeser, M., Aust, S., Otte, C., Pruessner, J. C., Böker, H., Bajbouj, M., \& Grimm, S. (2014). Early life stress modulates amygdala-prefrontal functional connectivity: Implications for oxytocin effects. Human Brain Mapping, 35(10), 5328-5339. https://doi.org/10.1002/hbm.22553

Fareri, D. S., \& Tottenham, N. (2016). Effects of early life stress on amygdala and striatal development. Developmental Cognitive Neuroscience, 19, 233-247. https://doi.org/10.1016/j.dcn.2016.04. 005

Finlon, K. J., Izard, C. E., Seidenfeld, A., Johnson, S. R., Cavadel, E. W., Ewing, E. S. K., \& Morgan, J. K. (2015). Emotion-based preventive intervention: Effectively promoting emotion knowledge and adaptive behavior among at-risk preschoolers. Development and Psychopathology, 27, 1353-1365. https://doi.org/10.1017/ S0954579414001461

Fisher, P. A., Frenkel, T. I., Noll, L. K., Berry, M., \& Yockelson, M. (2016). Promoting healthy child development via a two-generation translational neuroscience framework: The filming interactions to nurture development video coaching program. Child Development Perspectives, 10(4), 251-256. https://doi.org/10.1111/cdep.12195

Fortuna, L. R., Tolou-Shams, M., Robles-Ramamurthy, B., \& Porche, M. V. (2020). Inequity and the Disproportionate Impact of COVID-19 on Communities of Color in the United States: The Need for a Trauma-Informed Social Justice Response. Psychological Trauma: Theory, Research, Practice, and Policy, 12(5), 443-445. https://doi. org/10.1037/tra0000889

Frankenhuis, W. E. (2016). Environmental predictability. Encyclopedia of Evolutionary Psychological Science, 1-3. https://doi.org/10. 1007/978-3-319-16999-6

Fries, A., Moragues, N., Caldji, C., Hellhammer, D. H., \& Meaney, M. J. (2004). Preliminary evidence of altered sensitivity to benzodiazepines as a function of maternal care in the rat. Annals of the New York Academy of Sciences, 1032(1), 320-323. https://doi.org/10. 1196/annals.1314.051

Gassman-Pines, A., \& Gennetian, L. A. (2020). COVID-19 job and income loss jeopardize child well-being: Income support policies can help (Issue 9). https://www.srcd.org/research/covid-19-job-andincome-loss-jeopardize-child-well-being-income-support-policiescan-help?utm_source $=$ SRCD+General+Interest + List\&utm campaign $=7 \mathrm{a} 0$ bee $6 \mathrm{e} 3 \mathrm{e}$-EMAIL CAMPAIGN $202006 \quad 0503$ 03_COPY_01\&utm_medium $=$ email\&utm_term $=0$ e
Gee, D. G., Gabard-Durnam, L. J., Flannery, J., Goff, B., Humphreys, K. L., Telzer, E. H., Hare, T. A., Bookheimer, S. Y., \& Tottenham, N. (2013). Early developmental emergence of human amygdalaprefrontal connectivity after maternal deprivation. Proceedings of the National Academy of Sciences of the United States of America, 110(39), 15638-15643. https://doi.org/10.1073/pnas.1307893110

Gee, D. G., Gabard-Durnam, L., Telzer, E. H., Humphreys, K. L., Goff, B., Shapiro, M., Flannery, J., Lumian, D. S., Fareri, D. S., Caldera, C., \& Tottenham, N. (2014). Maternal buffering of human amygdala-prefrontal circuitry during childhood but not during adolescence. Psychological Science, 25(11), 2067-2078. https://doi. org/10.1177/0956797614550878

Glynn, L. M., \& Baram, T. Z. (2019). The influence of unpredictable, fragmented parental signals on the developing brain. Frontiers in Neuroendocrinology, 100736. https://doi.org/10.1016/J.YFRNE. 2019.01.002

Goldstein, D. S., \& McEwen, B. S. (2002). Allostasis, homeostasis, and the nature of stress. Stress, 5, 55-58. https://doi.org/10.1080/ 10253890290012345

Grupe, D. W., \& Nitschke, J. B. (2013). Uncertainty and anticipation in anxiety: An integrated neurobiological and psychological perspective. Nature Reviews Neuroscience, 14(7), 488-501. https://doi.org/ $10.1038 / \mathrm{nrn} 3524$

Gunnar, M. R., Hostinar, C. E., Sanchez, M. M., Tottenham, N., \& Sullivan, R. M. (2015). Parental buffering of fear and stress neurobiology: Reviewing parallels across rodent, monkey, and human models. Social Neuroscience, 10(5), 474-478. https://doi.org/10. 1080/17470919.2015.1070198

Hallers-Haalboom, E. T., Groeneveld, M. G., van Berkel, S. R., Endendijk, J. J., van der Pol, L. D., Linting, M., BakermansKranenburg, M. J., \& Mesman, J. (2017). Mothers' and fathers' sensitivity with their two children: A longitudinal study from infancy to early childhood. Developmental Psychology, 53(5), 860-872. https://doi.org/10.1037/dev0000293

Harms, M. B., Shannon Bowen, K. E., Hanson, J. L., \& Pollak, S. D. (2018). Instrumental learning and cognitive flexibility processes are impaired in children exposed to early life stress. Developmental Science, 21(4), 1-13. https://doi.org/10.1111/desc.12596

Harnett, N. G., Wheelock, M. D., Wood, K. H., Ladnier, J. C., Mrug, S., \& Knight, D. C. (2015). Affective state and locus of control modulate the neural response to threat. NeuroImage, 121, 217-226. https://doi.org/10.1016/J.NEUROIMAGE.2015.07.034

Harris, R. A., Qualter, P., \& Robinson, S. J. (2013). Loneliness trajectories from middle childhood to pre-adolescence: Impact on perceived health and sleep disturbance. Journal of Adolescence, 36(6), 12951304. https://doi.org/10.1016/j.adolescence.2012.12.009

Hashimoto, T., Takeuchi, H., Taki, Y., Sekiguchi, A., Nouchi, R., Kotozaki, Y., Nakagawa, S., Miyauchi, C. M., Iizuka, K., Yokoyama, R., Shinada, T., Yamamoto, Y., Hanawa, S., Araki, T., Hashizume, H., Kunitoki, K., \& Kawashima, R. (2015). Neuroanatomical correlates of the sense of control: Gray and white matter volumes associated with an internal locus of control. NeuroImage, 119, 146-151. https://doi.org/10.1016/J. NEUROIMAGE.2015.06.061

Hasson, U. (2017). The neurobiology of uncertainty: Implications for statistical learning. Philosophical Transactions of the Royal Society B: Biological Sciences, 372(1711), 20160048. https://doi. org/10.1098/rstb.2016.0048

Hawkley, L. C., \& Capitanio, J. P. (2015). Perceived social isolation, evolutionary fitness and health outcomes: A lifespan approach. Philosophical Transactions of the Royal Society B: Biological Sciences, 370(1669), 20140114. https://doi.org/10.1098/rstb.2014. 0114

Henry, J. (1992). Biological basis of the stress response. Integrative Physiological and Behavioral Science, 27(1), 66-83. https://doi. org/10.1007/BF02691093 
Herringa, R. J., Burghy, C. A., Stodola, D. E., Fox, M. E., Davidson, R. J., \& Essex, M. J. (2016). Enhanced Prefrontal-Amygdala Connectivity Following Childhood Adversity as a Protective Mechanism Against Internalizing in Adolescence. Biological Psychiatry: Cognitive Neuroscience and Neuroimaging, 1(4), 326-334. https://doi.org/10.1016/J.BPSC.2016.03.003

Hilt, L. M., \& Pollak, S. D. (2013). Characterizing the Ruminative Process in Young Adolescents. Journal of Clinical Child \& Adolescent Psychology, 42(4), 519-530. https://doi.org/10.1080/ 15374416.2013.764825

Hofmann, S. G., Asnaani, A., Vonk, I. J. J., Sawyer, A. T., \& Fang, A. (2012). The efficacy of cognitive behavioral therapy: A review of meta-analyses. In Cognitive Therapy and Research (Vol. 36, Issue 5, pp. 427-440). Springer New York LLC. https://doi.org/10.1007/ s10608-012-9476-1

Hostinar, C. E., \& Gunnar, M. R. (2013a). Future Directions in the Study of Social Relationships as Regulators of the HPA Axis Across Development. Journal of Clinical Child \& Adolescent Psychology, 42(4), 564-575. https://doi.org/10.1080/15374416.2013.804387

Hostinar, C. E., \& Gunnar, M. R. (2013b). The developmental effects of early life stress. Current Directions in Psychological Science, 22(5), 400-406. https://doi.org/10.1177/0963721413488889

Hostinar, C. E., Johnson, A. E., \& Gunnar, M. R. (2015). Early social deprivation and the social buffering of cortisol stress responses in late childhood: An experimental study. Developmental Psychology, 51(11), 1597-1608. https://doi.org/10.1037/dev0000029

Jamieson, J. P., Hangen, E. J., Lee, H. Y., \& Yeager, D. S. (2018). Capitalizing on appraisal processes to improve affective responses to social stress. Emotion Review, 10(1), 30-39. https://doi.org/10. $1177 / 1754073917693085$

Kalil, A., Mayer, S., \& Shah, R. (2020). Impact of the COVID-19 Crisis on Family Dynamics in Economically Vulnerable Households. SSRN Electronic Journal https://doi.org/10.2139/ssrn.3706339

Korte, S. M., Buwalda, B., Bouws, G. A. H., Koolhaas, J. M., Maes, F. W., \& Bohus, B. (1992). Conditioned neuroendocrine and cardiovascular stress responsiveness accompanying behavioral passivity and activity in aged and in young rats. Physiology \& Behavior, 51(4), 815-822. https://doi.org/10.1016/0031-9384(92)90120-Q

Korte, S. M., De Boer, S. F., De Kloet, E. R., \& Bohus, B. (1995). Anxiolytic-like effects of selective mineralocorticoid and glucocorticoid antagonists on fear-enhanced behavior in the elevated plusmaze. Psychoneuroendocrinology, 20(4), 385-394. https://doi.org/ 10.1016/0306-4530(94)00069-7

Koss, K. J., \& Gunnar, M. R. (2017). Annual Research Review: Early adversity, the hypothalamic-pituitary-adrenocortical axis, and child psychopathology. Journal of Child Psychology and Psychiatry, 59(4), 327-346. https://doi.org/10.1111/jcpp.12784

Ladd, G. W., \& Ettekal, I. (2013). Peer-related loneliness across early to late adolescence: Normative trends, intra-individual trajectories, and links with depressive symptoms. Journal of Adolescence, 36(6), 1269-1282. https://doi.org/10.1016/j.adolescence.2013.05.004

Lawson, M., Piel, M. H., \& Simon, M. (2020). Child Maltreatment during the COVID-19 Pandemic: Consequences of Parental Job Loss on Psychological and Physical Abuse Towards Children. Child Abuse and Neglect, 110(P2), 104709. https://doi.org/10.1016/j.chiabu. 2020.104709

Lazarus, R. S. (1990). Theory-based stress measurement. Psychological Inquirty, 1(1), 3-13.

Lê Cook, B, Trinh, N. H., Li, Z., Hou, S. S. Y., \& Progovac, A. M. (2017). Trends in racial-ethnic disparities in access to mental health care, 2004-2012. Psychiatric Services, 68(1), 9-16. https://doi.org/ 10.1176/appi.ps.201500453

Lee, C. M., Cadigan, J. M., \& Rhew, I. C. (2020). Increases in Loneliness Among Young Adults During the COVID-19 Pandemic and Association With Increases in Mental Health Problems. Journal of
Adolescent Health, 67(5), 714-717. https://doi.org/10.1016/j. jadohealth.2020.08.009

Li, L. Z., \& Wang, S. (2020). Prevalence and predictors of general psychiatric disorders and loneliness during COVID-19 in the United Kingdom. Psychiatry Research, 291(June), 113267. https://doi. org/10.1016/j.psychres.2020.113267

Liu, D., Diorio, J., Day, J. C., Francis, D. D., \& Meaney, M. J. (2000). Maternal care, hippocampal synaptogenesis and cognitive development in rats. Nature Neuroscience, 3(8), 799-806. https://doi.org/ 10.1038/77702

Loman, M. M., \& Gunnar, M. R. (2010). Early experience and the development of stress reactivity and regulation in children. Neuroscience and Biobehavioral Reviews, 34(6), 867-876. https:// doi.org/10.1016/j.neubiorev.2009.05.007

Manuck, S. B., Cohen, S., Rabin, B. S., Muldoon, M. F., \& Bachen, E. A. (1991). Individual differences in cellular immune response to stress. Psychological Science, 2(2), 111-115. https://doi.org/10.1111/j. 1467-9280.1991.tb00110.x

Masten, C. L., Telzer, E. H., Fuligni, A. J., Lieberman, M. D., \& Eisenberger, N. I. (2012). Time spent with friends in adolescence relates to less neural sensitivity to later peer rejection. SCAN, 7, 106114. https://doi.org/10.1093/scan/nsq098

McEwen, B. S. (2012). Brain on stress: How the social enviornment gets under the skin. PNAS, 109(Suppl 2), 17180-17185. https://doi.org/ 10.1073/pnas.95.9.5335

McEwen, B. S. (2017a). Neurobiological and systemic effects of chronic stress. Chronic Stress, 1, 1-11. https://doi.org/10.1177/ 2470547017692328

McEwen, B. S. (2017b). The resilient brain: Epigenetics, stress and the lifecourse. Psychoneuroendocrinology, 83, 76. https://doi.org/10. 1016/J.PSYNEUEN.2017.07.442

McEwen, B. S. (2019a). Resilience of the brain and body. Stress: Physiology, Biochemistry, and Pathology, 19-33. https://doi.org/ 10.1016/B978-0-12-813146-6.00002-3

McEwen, B. S. (2019b). What Is the Confusion With Cortisol? Chronic Stress, 3, 247054701983364. https://doi.org/10.1177/ 2470547019833647

McEwen, C. A., \& McEwen, B. S. (2017). Social structure, adversity, toxic stress, and intergenerational poverty: An early childhood model. Annual Review of Sociology, 43(1), 445-472. https://doi.org/10. 1146/annurev-soc-060116-053252

McLafferty, M., O’Neill, S., Armour, C., Murphy, S., \& Bunting, B. (2018). The mediating role of various types of social networks on psychopathology following adverse childhood experiences. Journal of Affective Disorders, 238, 547-553. https://doi.org/10.1016/J. JAD.2018.06.020

Mendes, W. B., Blascovich, J., Major, B., \& Seery, M. (2001). Challenge and threat responses during downward and upward social comparisons. European Journal of Social Psychology, 31(5), 477-497. https://doi.org/10.1002/ejsp.80

Mobbs, D., Petrovic, P., Marchant, J. L., Hassabis, D., Weiskopf, N., Seymour, B., Dolan, R. J., \& Frith, C. D. (2007). When fear is near: Threat imminence elicits prefrontal-periaqueductal gray shifts in humans. Science, 317, 1079-1083. https://doi.org/10.1126/science. 1144298

Molet, J., Maras, P. M., Kinney-Lang, E., Harris, N. G., Rashid, F., Ivy, A. S., Solodkin, A., Obenaus, A., \& Baram, T. Z. (2016). MRI uncovers disrupted hippocampal microstructure that underlies memory impairments after early-life adversity. Hippocampus, 26(12), 1618-1632. https://doi.org/10.1002/hipo.22661

Monroy, E., Hernández-Torres, E., Floréz, G., \& Flores, G. (2010) Maternal separation disrupts dendritic morphology of neurons in prefrontal cortex, hippocampus, and nucleus accumbens in male rat offspring. Journal of Chemical Neuroanatomy, 40(2), 93-101. https://doi.org/10.1016/J.JCHEMNEU.2010.05.005 
Moriceau, S., Shionoya, K., Jakubs, K., \& Sullivan, R. (2009). Early-life stress disrupts attachment learning: The role of amygdala corticosterone, locus ceruleus corticotropin releasing hormone, and olfactory bulb norepinephrine. The Journal of Neuroscience, 29(50), 15754 15755. https://doi.org/10.1523/jneurosci.4106-09.2009

Mormede, P., Dantzer, R., Michaud, B., Kelley, K. W., \& Le Moal, M. (1988). Influence of stressor predictability and behavioral control on lymphocyte reactivity, antibody responses and neuroendocrine activation in rats. Physiology and Behavior, 43(5), 577-583.

Muller, M. J. (2012). Will it hurt less if I believe I can control it? Influence of actual and perceived control on perceived pain intensity in healthy male individuals: A randomized controlled study. Journal of Behavioral Medicine, 35, 529-537.

Negriff, S. (2020). Childhood adversities and mental health outcomes: Does the perception or age of the event matter? Development and Psychopathology, 1-14. https://doi.org/10.1017/ S0954579420000048

Nephew, B. C., Huang, W., Poirier, G. L., Payne, L., \& King, J. A. (2017). Altered neural connectivity in adult female rats exposed to early life social stress. Behavioural Brain Research, 316, 225-233. https://doi.org/10.1016/J.BBR.2016.08.051

Obradović, J., Stamperdahl, J., Bush, N. R., Adler, N. E., \& Boyce, W. T. (2016). Biological Sensitivity to Context : The Interactive Effects of Stress Reactivity and Family Adversity on Socioemotional Behavior and School Readiness Published by: Wiley on behalf of the Society for Research in Child Development Stable URL : http://www.j. 81(1), 270-289.

Ottaviani, C., Thayer, J. F., Verkuil, B., Lonigro, A., Medea, B., Couyoumdjian, A., \& Brosschot, J. F. (2016). Physiological concomitants of perseverative cognition: A systematic review and metaanalysis. Psychological Bulletin, 142(3), 231-259. https://doi.org/ 10.1037/bul0000036

Palacios-Barrios, E. E., \& Hanson, J. L. (2019). Poverty and self-regulation: Connecting psychosocial processes, neurobiology, and the risk for psychopathology. Comprehensive Psychiatry, 90, 52-64. https:// doi.org/10.1016/j.comppsych.2018.12.012

Patrick, S. W., Henkhaus, L. E., Zickafoose, J. S., Lovell, K., Halvorson, A., Loch, S., Letterie, M., \& Davis, M. M. (2020). Well-being of Parents and Children During the COVID-19 Pandemic: A National Survey. Pediatrics, 146(4), e2020016824. https://doi.org/10.1542/ peds.2020-016824

Paulesu, E., Sambugaro, E., Torti, T., Danelli, L., Ferri, F., Scialfa, G., Sberna, M., Ruggiero, G. M., Bottini, G., \& Sassaroli, S. (2010). Neural correlates of worry in generalized anxiety disorder and in normal controls: a functional MRI study. Psychological Medicine, 40(1), 117-124. https://doi.org/10.1017/S0033291709005649

Pechtel, P., \& Pizzagalli, D. A. (2011). Effects of early life stress on cognitive and affective function: An integrated review of human literature. Psychopharmacology, 214(1), 55-70. https://doi.org/10. 1007/s00213-010-2009-2

Peters, A., McEwen, B. S., \& Friston, K. J. (2017). Uncertainty and stress: Why it causes diseases and how it is mastered by the brain. Progress in Neurobiology, 156, 164-188. https://doi.org/10.1016/j. pneurobio.2017.05.004

Pollak, S. D. (2015). Developmental psychopathology: Recent advances and future challenges. World Psychiatry, 14(3), 262-269. https:// doi.org/10.1002/wps.20237

Porges, S. W. (2015). Making the world safe for our children: Downregulating defence and up-regulating social engagement to "optimise" the human experience. Children Australia, 40(2), 114-123. https://doi.org/10.1017/cha.2015.12

Prime, H., Wade, M., \& Browne, D. T. (2020). Risk and resilience in family well-being during the COVID-19 pandemic. American Psychologist, undefined(undefined), undefined. https://doi.org/10. 1037/amp0000660
Pruessner, J. C., Baldwin, M. W., Dedovic, K., Renwick, R., Mahani, N. K., Lord, C., Meaney, M., \& Lupien, S. (2005). Self-esteem, locus of control, hippocampal volume, and cortisol regulation in young and old adulthood. NeuroImage, 28(4), 815-826. https://doi.org/10. 1016/J.NEUROIMAGE.2005.06.014

Pruessner, J. C., Dedovic, K., Khalili-Mahani, N., Engert, V., Pruessner, M., Buss, C., Renwick, R., Dagher, A., Meaney, M. J., \& Lupien, S. (2008). Deactivation of the limbic system during acute psychosocial stress: Evidence from positron emission tomography and functional magnetic resonance imaging studies. Biological Psychiatry, 63(2), 234-240. https://doi.org/10.1016/J.BIOPSYCH.2007.04.041

Richtel, M. (2020). Childhood without other children: A generation is raised in quarantine. New York Times. https://www.nytimes.com/ 2020/12/09/health/Covid-toddlers-playdates.html

Rincón-Cortés, M., \& Sullivan, R. M. (2016). Emergence of social behavior deficit, blunted corticolimbic activity and adult depressionlike behavior in a rodent model of maternal maltreatment. Translational Psychiatry, 6(10), e930. https://doi.org/10.1038/tp. 2016.205

Risbrough, V. B., Glynn, L. M., Davis, E. P., Snadman, C. A., Obenause, A., Stern, H. S., Keator, D. B., Yassa, M. A., Baram, T. Z., \& Baker, D. G. (2018). Does anhedonia presage increased risk of posttraumatic stress disorder. In E. Vermetten, D. G. Baker, \& V. B. Risbrough (Eds.), Behavioral Neurobiology of PTSD. Springer. https://doi.org/ $10.1007 / 7854$

Roy, M. P., Kirschbaum, C., \& Steptoe, A. (2001). Psychological, cardiovascular, and metabolic correlates of individual differences in cortisol stress recovery in young men. Psychoneuroendocrinology, 26(4), 375-391. https://doi.org/10.1016/S0306-4530(00)00061-5

Salganik, M. J., Lundberg, I., Kindel, A. T., Ahearn, C. E., Al-Ghoneim, K., Almaatouq, A., Altschul, D. M., Brand, J. E., Carnegie, N. B., Compton, R. J., Datta, D., Davidson, T., Filippova, A., Gilroy, C., Goode, B. J., Jahani, E., Kashyap, R., Kirchner, A., McKay, S., ... McLanahan, S. (2020). Measuring the predictability of life outcomes with a scientific mass collaboration. Proceedings of the National Academy of Sciences, 201915006. https://doi.org/10. 1073/pnas.1915006117

Sanchez, M. M., McCormack, K. M., \& Howell, B. R. (2015). Social buffering of stress responses in nonhuman primates: Maternal regulation of the development of emotional regulatory brain circuits. Social Neuroscience, 10(5), 512-526. https://doi.org/10.1080/ 17470919.2015.1087426

Sapolsky, R. M. (2004). Why zebras don't get ulcers (3rd ed.). Holt Paperbacks.

Sapolsky, R. M. (2015). Stress and the brain: Individual variability and the inverted-U. Nature Neuroscience, 18(10), 1344-1346. https:// doi.org/10.1038/nn.4109

Seltzer, L. J., Ziegler, T. E., \& Pollak, S. D. (2010). Social vocalizations can release oxytocin in humans. Proceedings of the Royal Society B: Biological Sciences, 277(1694), 2661-2666. https://doi.org/10. 1098/rspb.2010.0567

Smith, K. E., \& Pollak, S. D. (2020). Rethinking Concepts and Categories for Understanding the Neurodevelopmental Effects of Childhood Adversity. Perspectives on Psychological Science, 174569162092072. https://doi.org/10.1177/1745691620920725

Soltani, A., \& Izquierdo, A. (2019). Adaptive learning under expected and unexpected uncertainty. Nature Reviews Neuroscience, 1. https://doi.org/10.1038/s41583-019-0180-y

Spinelli, S., Chefer, S., Suomi, S. J., Higley, J. D., Barr, C. S., \& Stein, E. (2009). Early-life stress induces long-term morphologic changes in primate brain. Archives of General Psychiatry, 66(6), 658. https:// doi.org/10.1001/archgenpsychiatry.2009.52

Sullivan, R. M., \& Opendak, M. (2018). Developmental and neurobehavioral transitions in survival circuits. Current Opinion in Behavioral Sciences, 24, 50-55. https://doi.org/10.1016/j.cobeha.2018.03.005 
Sutin, A. R., Luchetti, M., \& Terracciano, A. (2020). Has loneliness increased during COVID-19? Comment on "Loneliness: A signature mental health concern in the era of COVID-19" Psychiatry Research, 291(January), 113295. https://doi.org/10.1016/j. psychres.2020.113295

Tottenham, N. (2015). Social scaffolding of human amygdalamPFCcircuit development. Social Neuroscience, 10(5), 489-499. https://doi.org/10.1080/17470919.2015.1087424

Tull, M. T., Edmonds, K. A., Scamaldo, K. M., Richmond, J. R., Rose, J. P., \& Gratz, K. L. (2020). Psychological Outcomes Associated with Stay-at-Home Orders and the Perceived Impact of COVID-19 on Daily Life. Psychiatry Research, 289(April), 113098. https://doi. org/10.1016/j.psychres.2020.113098

Turecki, G., \& Meaney, M. J. (2016). Effects of the social environment and stress on glucocorticoid receptor gene methylation: A systematic review. Biological Psychiatry, 79(2), 87-96. https://doi.org/10. 1016/J.BIOPSYCH.2014.11.022

van Harmelen, A.-L., Gibson, J. L., St Clair, M. C., Owens, M., Brodbeck, J., Dunn, V., Lewis, G., Croudace, T., Jones, P. B., Kievit, R. A., \& Goodyer, I. M. (2016). Friendships and family support reduce subsequent depressive symptoms in at-risk adolescents. PLOS ONE, 11(5), e0153715. https://doi.org/10.1371/ journal.pone. 0153715

van Hasselt, F. N., Cornelisse, S., Yuan Zhang, T., Meaney, M. J., Velzing, E. H., Krugers, H. J., \& Joëls, M. (2012). Adult hippocampal glucocorticoid receptor expression and dentate synaptic plasticity correlate with maternal care received by individuals early in life. Hippocampus, 22(2), 255-266. https://doi.org/10.1002/hipo.20892

Vanhalst, J., Goossens, L., Luyckx, K., Scholte, R. H. J., \& Engels, R. C. M. E. (2013). The development of loneliness from mid- to late adolescence: Trajectory classes, personality traits, and psychosocial functioning. Journal of Adolescence, 36(6), 1305-1312. https://doi. org/10.1016/j.adolescence.2012.04.002

Vedhara, K., Hyde, J., Gilchrist, I. ., Tytherleigh, M., \& Plummer, S. (2000). Acute stress, memory, attention and cortisol. Psychoneuroendocrinology, 25(6), 535-549. https://doi.org/10. 1016/S0306-4530(00)00008-1
Veenema, A. H., Meijer, O. C., de Kloet, E. R., Koolhaas, J. M., \& Bohus, B. G. (2003). Differences in basal and stress-induced HPA regulation of wild house mice selected for high and low aggression. Hormones and Behavior, 43(1), 197-204. https://doi.org/10.1016/ S0018-506X(02)00013-2

Wager, T. D., Waugh, C. E., Lindquist, M., Noll, D. C., Fredrickson, B. L., \& Taylor, S. F. (2009). Brain mediators of cardiovascular responses to social threat: Part I: Reciprocal dorsal and ventral subregions of the medial prefrontal cortex and heart-rate reactivity. NeuroImage, 47(3), 821-835. https://doi.org/10.1016/J. NEUROIMAGE.2009.05.043

Weaver, I. C. G., Cervoni, N., Champagne, F. A., D'Alessio, A. C., Sharma, S., Seckl, J. R., Dymov, S., Szyf, M., \& Meaney, M. J. (2004). Epigenetic programming by maternal behavior. Nature Neuroscience, 7(8), 847-854. https://doi.org/10.1038/nn1276

Will, G., van Lier, P. A. C., Crone, E. A., \& Güroğlu, B. (2016). Chronic Childhood Peer Rejection is Associated with Heightened Neural Responses to Social Exclusion During Adolescence. Journal of Abnormal Child Psychology, 44(1), 43-55. https://doi.org/10. 1007/s10802-015-9983-0

Zajac, L., Raby, K. L., \& Dozier, M. (2019). Attachment state of mind and childhood experiences of maltreatment as predictors of sensitive care from infancy through middle childhood: Results from a longitudinal study of parents involved with Child Protective Services. Development and Psychopathology, 31(1), 113-125. https://doi. org/10.1017/S0954579418001554

Zhang, T., Chrétien, P., Meaney, M. J., \& Gratton, A. (2005). Influence of naturally occurring variations in maternal care on prepulse inhibition of acousitc startle and the medial prefrontal cortical dopamine response to stress in adult rats. The Journal of Neuroscience, 25(6), 1493-1502. https://doi.org/10.1523/jneurosci.3293-04.2005

Publisher's note Springer Nature remains neutral with regard to jurisdictional claims in published maps and institutional affiliations. 